\title{
HAY VIDA DESPUÉS DE LA MINA... INDUSTRIA Y MEDIOAMBIENTE Y LITERATURA EN LA CUENCA MINERA DE UTRILLAS (TERUEL)
}

\author{
(c) (1) (3) \\ Carmen Valero Garcés \\ Grupo FITISPos y Gieco. Universidad de Alcalá ${ }^{1}$
}

\begin{abstract}
Resumen
Utrillas (Teruel) forma parte de la Comarca de Cuencas Mineras de la Comunidad Autónoma de Aragón, siendo además capital administrativa de la misma. Desde el siglo XI hay vestigios de la búsqueda de minerales en esta zona hasta que con el inicio del siglo XXI cesa la producción minera a cielo abierto. Desde entonces y hasta hoy en día el empeño de estas gentes utrillenses ha sido recuperar su destrozada zona y continuar con la vida. El objetivo de este artículo es dar cuenta de esa recuperación en tres ámbitos distintos: Recuperación medioambiental, recuperación socio económica y restauración del patrimonio minero.
\end{abstract}

Palabras clave: Minería, Medioambiente, Patrimonio industrial, Recuperación, Teruel, Utrillas, Aragón.

\begin{abstract}
Utrillas (Teruel) is part of the region and administrative capital of the Comarca de Cuencas Mineras (coalfield county) in the Autonomous Community of Aragón. Traces of the search for minerals in this area come from the $11^{\text {th }}$ century until the beginning of $21^{\text {st }}$ century when open pit production ends. From then until nowadays the efforts of these people have been concentrated in recovering the desolated area and getting on with their life. The aim of this article is to account for this recovery in three different areas: environmental recovery, socio economic recovery and the restoration of mining heritage.
\end{abstract}

Keywords: Mining, Environment, Industrial heritage, Recovery, Teruel, Utrillas.

\section{INTRODUCCIÓN}

Utrillas (Teruel) forma parte de la Comarca de Cuencas Mineras de Aragón, siendo además capital administrativa de la misma. Desde el siglo XI hay vestigios de la búsqueda de minerales en esta zona; en el siglo XX se intensifica y también finaliza su producción. En esta etapa, su historia está ligada a Minas y Ferrocarril de Utrillas, S.A (MFU S.A). En 1966 dejó de circular el ferrocarril; en 1991 se produce el cierre de las minas principales de interior; en 2001 cesa la producción a cielo abierto y en 2003 deja de existir MFU S.A. Desde entonces y hasta hoy en día el empeño de estas gentes utrillenses ha sido recuperar su zona y continuar con la vida. El objetivo de este artículo es dar cuenta de esa recuperación en tres ámbitos distintos: recuperación medioambiental, recuperación socio económica y restauración del patrimonio minero.

Los datos provienen de publicaciones sobre la zona, investigación en los archivos

1 Universidad de Alcalá. Correo: Carmen.valero@uah.es. Recibido: 1-09-2014. Aceptado: 1-12-2014 
municipales sobre proyectos de recuperación en los distintos ámbitos y la opinión de sus ciudadanos sobre el pasado, presente y futuro de Utrillas.

Esperamos que los resultados de esta investigación sirvan para dar a conocer el esfuerzo de comarcas deprimidas en favor de un crecimiento sostenible manteniendo la biodiversidad en vez de caer en la destrucción del entorno. Trataremos de conjugar industria,medioambiente y literatura.

\section{ORÍGENES Y BREVE HISTORIA MINERA DE UTRILLAS}

Los orígenes de Utrillas nos remiten a la época íbera y romana, en la que se originó la población y su núcleo como tal. Existen restos que nos muestran que por aquel entonces, existió el asentamiento del que derivará luego el pueblo. Es en la época de la Reconquista cuando se comenzó a llamar pueblo a Utrillas debido a que pasó a formar parte de Montalbán y a estar bajo la protección de los caballeros de Santiago. Más tarde pasó a formar parte de la Corona de Aragón con Fernando el Católico y con el paso de los años, la población rodeó el castillo y Utrillas fue nombrada Concejo para pasar a ser luego Villa Real.

Hablar de la historia de Utrillas es hablar de la minería de las Cuencas Mineras de la provincia de Teruel. La historia de la minería es antigua: estas zonas de extracción tienen su origen en el Mesozoico.

Hay testimonios que indican que ya en el siglo XI se buscaban materiales en la tierra de Utrillas. El azabache y su intenso negro era pretendido con ahínco en esas épocas. Se vendía a comerciantes de Levante que negociaban con genoveses. A partir del siglo XVIII comienza la extracción a gran escala. El desarrollo que comienza derivará en el siglo XX en una gran plataforma de extracción minera a través de guías y bajo tierra. El aumento de la extracción minera a cielo abierto derivó en el parón de esta producción en el año 1991, cuando se clausuró la última mina de interior: el Pozo Pilar.

Durante este período, la principal empresa que explotó el carbón a gran escala fue la Compañía Minas y Ferrocarril de Utrillas, S.A. (MFU S.A.). Esta empresa fue fundada en el Casino Mercantil de Zaragoza a fecha 14 de mayo de 1900 y dejó de existir como tal en 2003. El listado de las instalaciones mineras que hubo antes de su cierre da cuenta de su importancia:

La Mina Cabezo de las Eras, situada a 100 metros de la población junto a las eras de Utrillas.

La Mina Serna, situada entre Utrillas y Las Barriadas del Sur, y de la que todavía puede verse parte de la entrada a la mina, siendo estas dos las primeras que comenzó a explotar MFU S.A.

La Mina Sur, creada sobre 1910, que fue una galería abierta para dar continuidad a las instalaciones que había por aquel momento y salvar una distancia de 2,5 kilómetros. 
Esta mina fue explotada hasta los años 1980.

Pozo Los Calderones, pozo que se empezó a construir sobre el 1910 cerca del poblado minero de Barriadas del Sur.

Pozo de Santa Bárbara, que se comenzó a perforar en el año1914 hasta una profundidad de 160 metros.

Mina Oeste, a 400 metros de Utrillas, cuya explotación comenzó en 1912, llamada popularmente La Higuera.

Mina Santiago, cuya explotación comenzó en 1926.

Galería Mina Capa Tercera, situada junto a la explanada del Pozo de Santa Bárbara.

Mina Pozo Pilar, a unos 150 metros de Escucha dirección sur, cuya explotación se inicia a partir de 1970 para surtir de carbón a la central térmica de Escucha, construida por Unión Térmica, S.A. Esta mina llegó a ser una de las más modernas de Europa.

En cuanto a la economía de la zona, debido al auge de la minería, las actividades relacionadas con el cultivo de la tierra o la cría de animales para producción no es la actividad, ni lo ha sido en tiempos pasados, más predominante en el territorio municipal. El carbón se extraía de sus minas y era la principal fuente de ingresos del lugar hasta 1991, año en que se cerró la última mina de interior y las extracciones a cielo abierto fueron cerrando progresivamente hasta el año 2003. En la actualidad no queda ninguna mina de carbón abierta y la industria existente se distribuye sobre todo en dos polígonos industriales: el Polígono Industrial Barriadas y el Polígono Industrial de Los Llanos. 


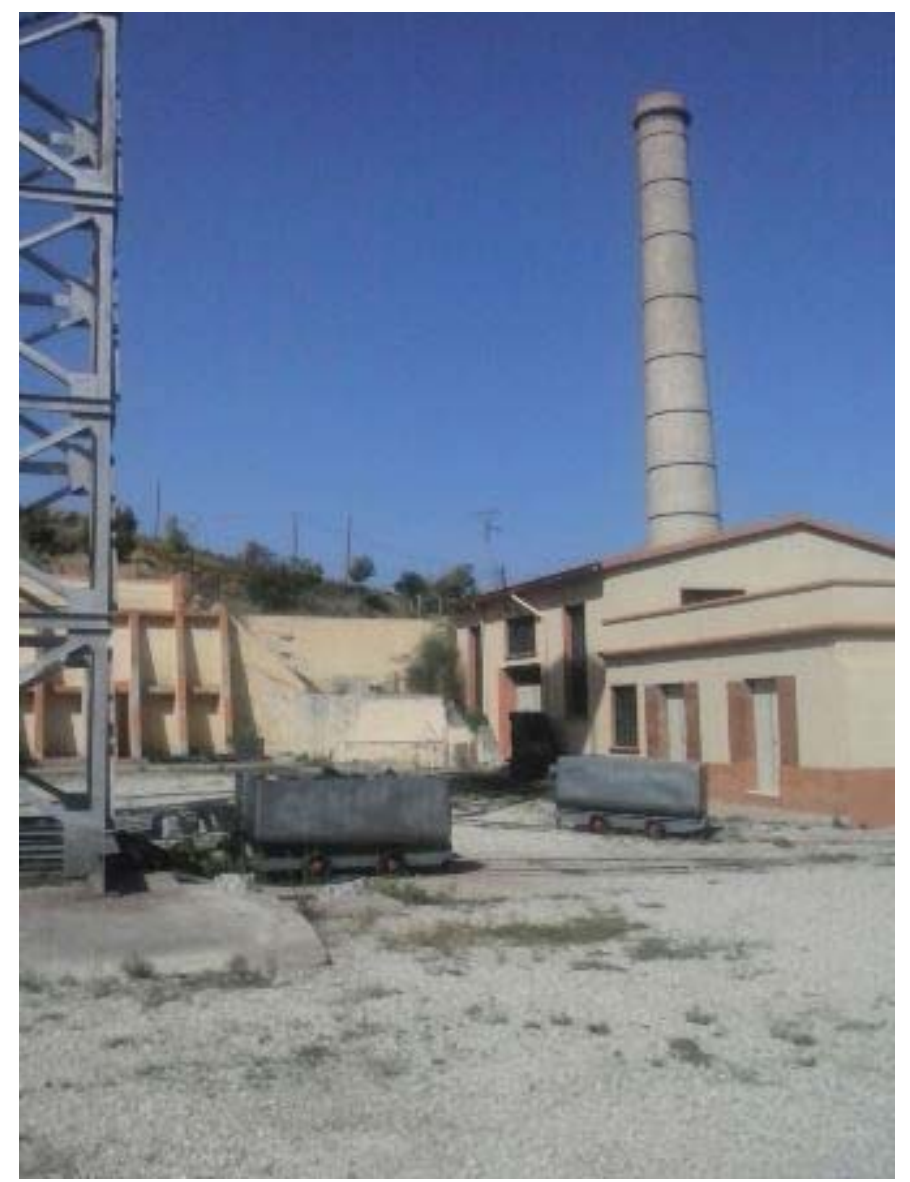

\section{CIERRE DE LA ACTIVIDAD MINERA E INICIO DE LA RECUPERACIÓN}

Utrillas es cabeza de la Comarca de las Cuencas Mineras. Está asentada al pie de la sierra de San Just, en la cordillera Ibérica y sobre el río Mena, con un clima plenamente continental, de temperaturas extremas y escasas lluvias. En la actualidad cuenta con una demografía envejecida tras el cierre de la actividad minera que trata de recuperarse poco a poco con esfuerzo. A modo de ejemplo y antes de entrar en detalles citemos algunos logros de estas gentes.

El 31 de marzo de 1966 fue el último día que circuló el ferrocarril que, desde 1904, unía Zaragoza con Utrillas y sus minas. Un largo recorrido que era completado por otros siete kilómetros de una vía de sesenta centímetros de ancho que subía desde la zona de los lavaderos a los pozos mineros. Ese día- 31 de marzo de 1966- cesó la actividad ferroviaria mientras continuaba la actividad minera en este confín turolense. Ahora, cinco décadas más tarde, las locomotoras de vapor que en tiempos circularon por esta zona vuelven a rodar gracias al empeño del ayuntamiento y los aficionados al ferrocarril.

Fue en septiembre de 2012, y coincidiendo con las fiestas patronales de Utrillas, cuando el Ayuntamiento de esta histórica villa minera y la Asociación de Amigos 
del Museo Minero de Utrillas presentaron su tren minero original, encabezado por la legendaria locomotora HULLA al frente de un coche de viajeros de esta misma línea, impecablemente restaurado, conocido en la zona como "El tranvía".

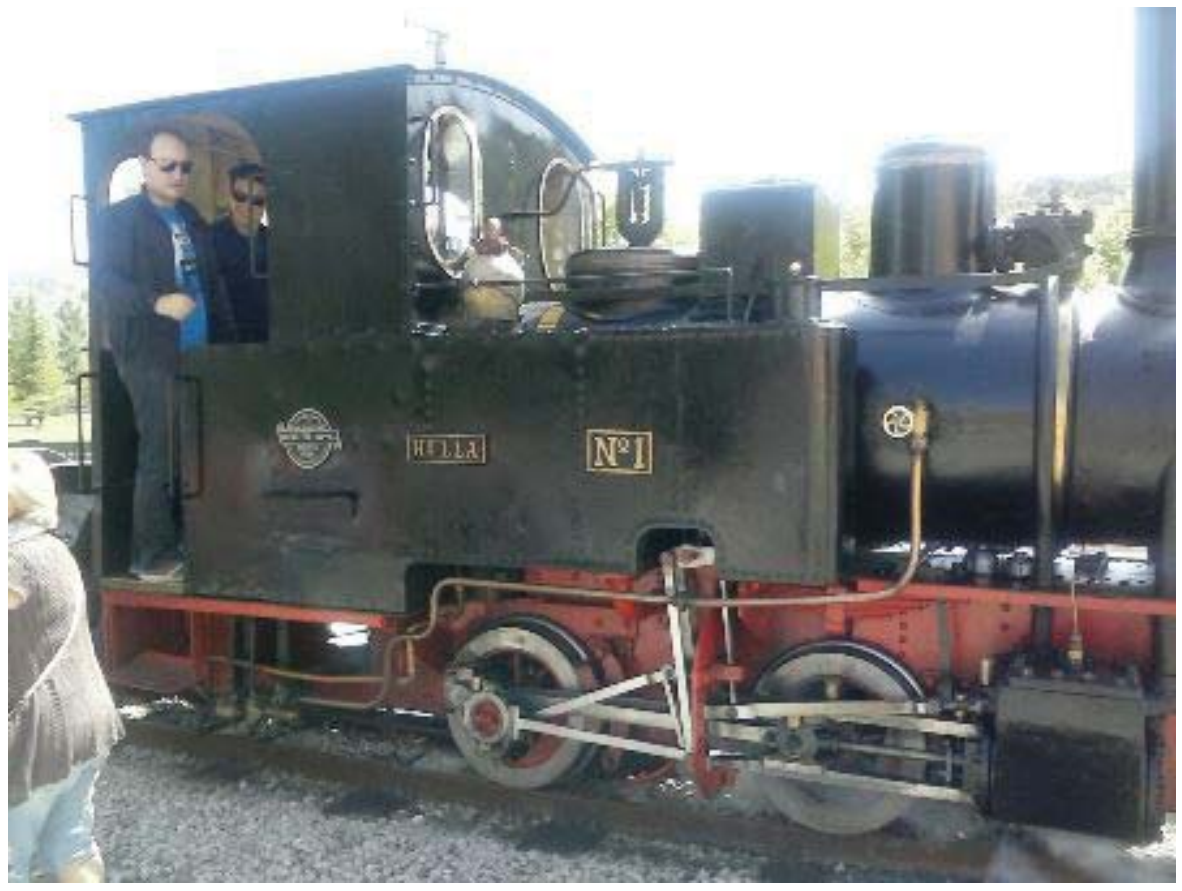

La información dada por la Asociación de Amigos del Museo Minero de Utrillas, "hija" de la AZAFT (Asociación Zaragozana de Amigos del Ferrocarril y los Tranvías), y motor de dinamización y coordinación de éstos no deja duda de su valor de restauración y recuperación del patrimonio industrial de la zona:

Así, la HULLA y "El tranvía” circulan de nuevo por este pequeño tramo de vía LavaderosMina como parte del proyecto de recuperación del trazado del ferrocarril original. Durante este recorrido, el visitante podrá contemplar algunos de los viejos edificios vinculados a las minas, estructuras ahora recuperadas para usos ligados a la interpretación y puesta en valor de este legado industrial y patrimonial, entre los que se cuentan:

- El Nuevo Museo Minero, ahora instalado en lo que antaño fue el hospital minero.

- Anexo a éste, se erige el Centro de Congresos.

- La antigua Casa de la Dirección de Minas y ferrocarriles de Utrillas ha sido rehabilitada como albergue.

- Un parque que da acceso a la hoy recuperada Mina de Santiago.

- La zona del Pozo de Santa Bárbara, considera la joya de la corona, donde, al pie del representativo castillete del Pozo, se podrá visitar sus instalaciones anexas, incluyendo el edificio del vestuario y aquél que alberga las dos calderas Borsig que movían los ascensores del pozo minero.

- En la misma zona del Pozo y en su localización original, las Antiguas Escuelas es hoy un Centro de Interpretación en el que el visitante podrá revivir el día a día de los escolares en un aula totalmente restaurada. En este espacio, conviven los más avanzados dispositivos interactivos y auténticas piezas históricas, que harán de su visita una experiencia inolvidable. (www.minasutrillas.es) 
Estas acciones conjuntas hacen que el patrimonio minero se vaya recuperando. Así las duchas de los mineros, las calderas que generaban el vapor, las primeras escuelas que construyó MFU S.A. para los hijos de los mineros, el castillete, el tren minero, etc. van cobrando vida nuevamente, intentando que perdure en el tiempo la tradición minera y que las generaciones posteriores puedan ver como durante un siglo la minería fue el modo de vida tanto en Utrillas como en la zona central de la comarca.

\title{
4. LA MFU S.A. Y EL FERROCARRIL
}

Dada la importancia MFU S.A. (Minas y Ferrocarriles de Utrillas S.A.) en la historia minera de esta zona, las páginas siguientes van dedicadas a esta empresa para poder entender mejor la recuperación del patrimonio minero.

Jesús Albero Gracia (2002), en su libro Cien años de la Constitución de la Compañía "Minas y Ferrocarril de Utrillas, S. A.", da muestras una vez más del sentir de estas gentes y su empeño por recuperarse a la vez que enfatiza la importancia del tren- uno de los motores hoy en día de atracción turística y fuente de ingresos.

Albero (2002: 10) advierte ya al principio:

\begin{abstract}
El autor de este escrito no es un profesional de la historia ni de la literatura, sino un simple aficionado que relata las vivencias y experiencias adquiridas entre las vías del FC, las locomotoras y las minas, interesándose por temas aragoneses que le cautivan y apasionan. Por tanto, con este opúsculo no trata de hacer historia (para eso ya están los historiadores) sino el de resaltar el centenario, y también, el de recordar y agradecer muy calurosamente a los fundadores de la Cía. Sobra merecimiento para ello, y sería injusto olvidarlo por parte de todos.
\end{abstract}

MFU S.A. fue la empresa que casi durante un siglo controló la explotación de los lignitos de la cuenca minera de Utrillas. La actividad de esta sociedad se inicia un 4 de marzo de 1900, fecha en la que se constituyó la empresa Minas y Ferrocarriles de Utrillas S.A. culminado un conjunto de difíciles gestiones, llevadas a cabo por los financieros Mariano y Santiago Baselga Ramírez, en los últimos meses de 1899 con la compra de las minas a sus propietarios. Inmediatamente después de consolidar las concesiones para la explotación de la cuenca, se acometió el proyecto de construcción de un ferrocarril para transportar el lignito, a través de Zaragoza, a los consumidores de toda España.

El ferrocarril fue inaugurado el 29 de septiembre de 1904, y al día siguiente, 30 de septiembre, comenzó a prestar servicio público, "siendo una gran mejora para la comarca al no existir en aquellas fechas otras vía de comunicación que caminos de herradura y carreteras con carros y diligencias de tracción animal." (Albero, 2002: 45)

A partir de esas fechas de principio de siglo XX es cuando se acomete la explotación de la cuenca minera de Utrillas a escala industrial, cuya producción de lignitos de 
gran calidad se incrementaría constantemente, exceptuando los años de la Guerra Civil en que la actividad minera apenas existió. En esta época de conflictos, tal y como describe Albero en las páginas siguientes, el ferrocarril se utilizó para el transporte de tropas y material de guerra. Acabada ésta, una vez reparados los desperfectos que sufrió la línea férrea, en el año 1940, se reanuda la producción y consiguientemente el transporte de carbón.

En los años siguientes (década de 1950) la empresa cambió de propietarios varias veces pero siguió llamándose Minas y Ferrocarril de Utrillas, siendo los años de mayor prosperidad. A final de la década de 1950, decrece el tráfico de carbón por la línea férrea debido a la fuerte competencia que supone el transporte por carretera y aunque la producción de carbón sigue aumentando, el mantenimiento del ferrocarril se hace insostenible.

Finalmente, y a pesar de la intervención del gobierno de la nación por medio de la empresa Ferrocarriles Españoles de Vía Estrecha (FEVE), el día 31 de marzo de 1966 se clausura definitivamente el ferrocarril Utrillas - Zaragoza. Y se continúa el transporte de carbón con camiones, principalmente a la central térmica de Escucha, situada a unos kilómetros de Utrillas, que absorbe casi toda su producción.

Durante una década más la explotación minera sigue ante la demanda de lignito para abastecer a las centrales térmicas turolenses de Aliaga, Escucha y al importante complejo de producción termoeléctrica de Andorra (Teruel)-Escatrón (Zaragoza) y Utrillas. Su zona de influencia crece de manera imparable, a la vez que se acometen planes urbanísticos que transforman la zona. En 1975 este crecimiento sufre el primer revés con el cierre de la Mina Santiago por su escasa productividad y costosa extracción. La siguiente mina se cerró en 1980 (La Mina del Sur), e inmediatamente después en 1981 se cerró el Pozo de Santa Bárbara. El 22 de noviembre de 1992 se paralizó definitivamente la actividad minera subterránea con el sellado mediante una gruesa capa de hormigón del Pozo del Pilar. Se continuó con explotaciones de carbón a cielo abierto para alimentar a centrales térmicas y con dificultades se mantuvo la extracción de lignito hasta el año 2003, año en el que finaliza la actividad minera en Utrillas. 


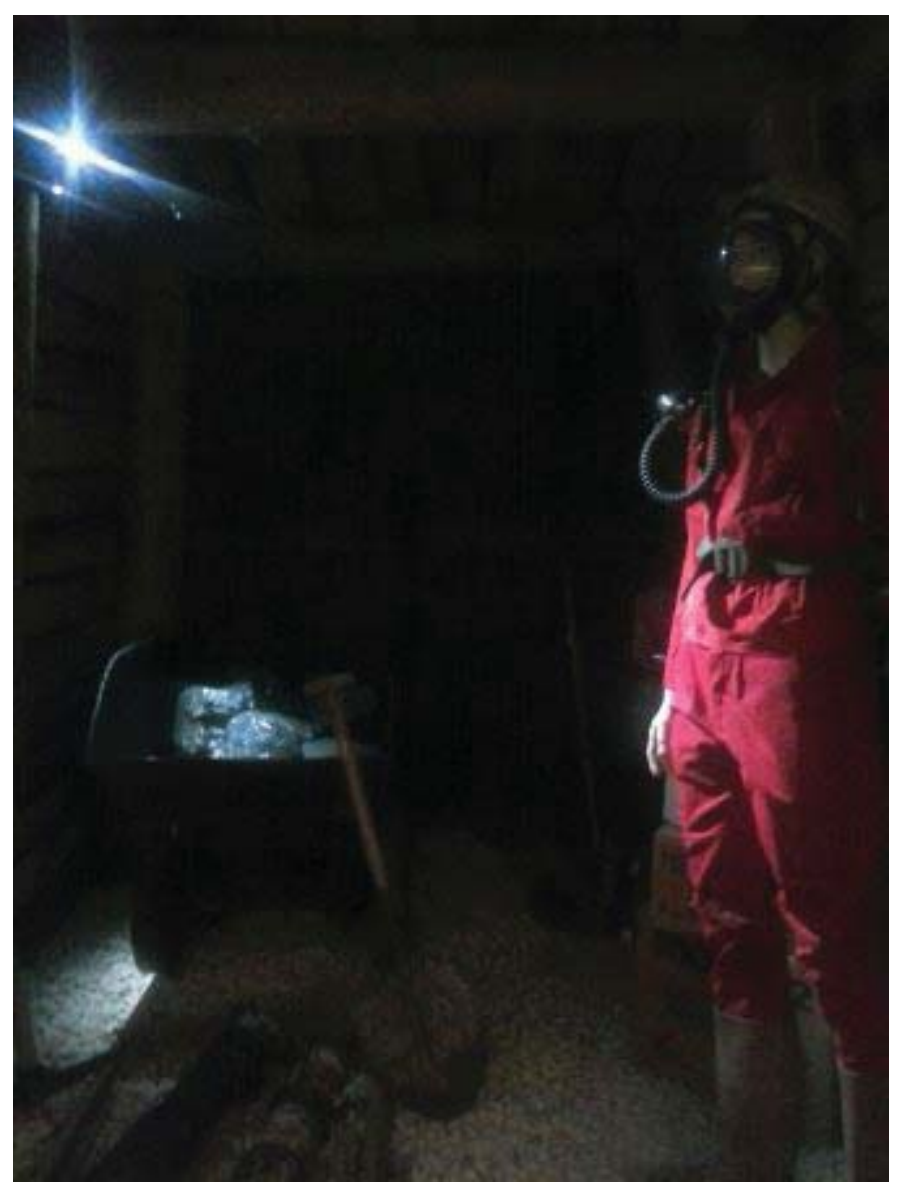

Tras este breve recorrido por la historia de la minería utrillense, dedicaremos las páginas siguientes a repasar cómo han vivido estas gentes desde entonces y qué ha sido de su paisaje, economía y patrimonio. Comenzaremos hablando de la recuperación medioambiental, para continuar con la recuperación socio-económica y finalizar con algunas notas sobre la recuperación del patrimonio minero, todo ello extraído de los archivos municipales, documentos y publicaciones científicas y obras literarias de sus paisanos escritas en torno a esta cuenca minera. El colofón lo pondrán las voces de estos utrillenses.

\section{RECUPERACIÓN MEDIOAMBIENTAL}

La zona de la Comarca de Cuencas Mineras de Teruel comprende la parte septentrional del Sistema Ibérico, en plena sierra de Sant Just, de gran riqueza geológica. En sus lindes se encuentran lugares como el Parque Cultural del Río Martín y el Parque Cultural del Maestrazgo, que aúnan la riqueza natural de un territorio con pinturas rupestres, multitud de aves rapaces, restos arqueológicos y yacimientos paleontológicos que le dan un gran valor al entorno. Ermitas como la de Nuestra Señora de la Estrella en Almudén, iglesias, como la antigua parroquial del Martín del Río y la espectacular iglesia de Santiago el Mayor en Montalbán o las torres mudéjares de 
Muniesa, forman, entre otras, el patrimonio de las tierras de carbón. A este patrimonio artístico se unen las características de su paisaje. Los testimonios de los conocedores de la zona dan fe de ello:

Los paisajes de la comarca "Cuenca mineras" se caracteriza por tener una orografía de colinas uniformes, no demasiado altas y desprovista de vegetación. Apenas se observan zonas forestales, únicamente en las vaguadas crecen los chopos, las encinas, los pinos silvestres, las hayas, los robles y algún álamo y eucalipto. (Albero, 2002: 168)

La época de mayor prosperidad de Utrillas fue en la década de 1970 y fue también la época de destrucción del paisaje. Francisco Randó (2004), en su sentido libro Un valle de ceniza, magnífica obra literaria dedicada a describir sus vivencias en este valle de cenizas, como él lo llama, y donde vivió el máximo esplendor de la zona con su declive total, deja clara constancia de ello. Randó es hijo del maestro que fue a Utrillas tras la Guerra Civil para hacerse cargo de una escuela de enseñanza primaria creada por la empresa MFU S.A. con el fin de educar a los hijos de los mineros y complementar la precaria escolarización de los niños del pueblo.

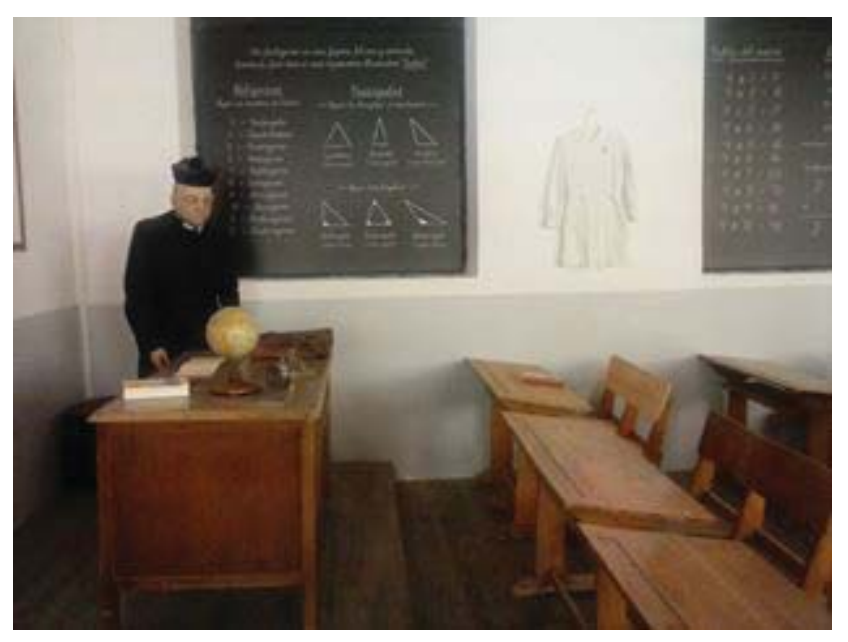

Randó (2004: 23), persona muy querida en el pueblo, escribe con respecto al paisaje:

Es mucho lo que me ha dado esta parte de la provincia de Teruel, árido, montañoso y frío que guardaba su riqueza en las minas de carbón, de las que hemos vivido varias generaciones, hasta que dejo de ser rentable su explotación. Es por ello que me duele tanto ver como el paso del tiempo, la desidia, el abandono y la marginación han convertido en un valle de cenizas una parte de estas comarcas que después de superar no pocas adversidades, desde el inicio del siglo $\mathrm{xx}$ y hasta los primeros años ochenta, ejemplo de vida y prosperidad acogiendo a gentes de toda procedencia.

Y continúa con el lamento como otras muchas personas de la zona que se quedaron o que emigraron: 
El Utrillas de mis recuerdos ha dejado de ser un pueblo minero- mi pueblo minero- Ahora lucha para sobrevivir y renace de sus propias cenizas almacenadas en inmensos escorialeslas escombreras ya apagadas que rodean el pueblo- y que dan, todavía, testimonio de que fue un pueblo vivo y próspero, situado en el centro de la provincia, a cerca de mil metros de altitud y rodeado de algunos de los montes más elevados del macizo Ibérico, como son la loma de San Just- al Sudeste- que supera los 1500 metros de altitud y la sierra llamada "Peña del Cid"- al Norte- por cuyas estribaciones discurre el rio Martín, recién nacido.( Randó 2004: 23)

$\mathrm{Y}$, como bien sabe el autor, ciertamente es un reto, absolutamente imprevisible y sumamente arriesgado, escribir sobre la que actualmente es una de las comarcas más deprimidas de España, enclavadas en una provincia que grita a los cuatro vientos que aun "existe" (Teruel existe), en su legítima aspiración de no perder el arbitrario tren del desarrollo.

Randó (2004: 17) enfatiza:

Una comarca que anteriormente fue denominada "Las Parameras Montalbinas" - toda una premonición- y que en la actualidad forma parte de una extensa zona enclavada en el centro de la provincia turolense llamada "Cuencas Mineras" -otra sangrante falacia, habida cuenta que la actividad minera en esta zona ha desaparecido casi por completo.

Sus comentarios casi al final del libro es todo un grito de salvación: "Si la popular frase 'Teruel existe' se esgrime a modo de denuncia para reclamar la atención sobre esta provincia, me gustaría que para Utrillas no fuese suficiente esa denuncia". Randó (2004: 266) concluye con la afirmación que es casi una premoción: “Utrillas volverá a brillar con luz propia y emergerá desde sus propias cenizas".

A la par que va desapareciendo la actividad minera va creciendo la conciencia por la recuperación del medioambiente ante la degradación palpable que con la explotación a cielo abierto era aún más visible.

Un resumen de información extraída en los archivos municipales de estudios llevados a cabo por estos proyectos con el fin de ejecutar acciones de mejora medioambiental muestra la influencia actual del pasado minero de la villa sobre el medio ambiente, e indican como principales alteraciones:

a) Sobre el medio geológico: cambios en la geomorfología del terreno con modificaciones de la topografía, aumento de riesgo de deslizamiento o desprendimiento, incremento de la tasa de erosión...

b) Sobre las aguas: 1.Subterráneas: alteración del régimen de caudales, destrucción de zona de recarga de acuíferos, contaminación de acuíferos. 2. Superficiales: modificación de la red de drenaje natural; turbiedad de las aguas, contaminación química.

c) Sobre la vegetación y cultivos: ocupación del suelo fértil, deforestación, desmontes, desbroces y aclaradas, aumento de polvo y contaminantes, eliminación del hábitat, moviente de tierras, aumento de pendiente y erosión. 
d) Sobre la fauna: pérdida del hábitat natural, aumento de ruidos, efecto barrera, cambio de actuación en curso de agua y contaminación de los mismos, aumento de tránsito, tendidos eléctricos...

e) Sobre el suelo: pérdida de suelo, alteración química y pérdida de calidad edáfica, desprendimientos, deslizamientos, polvo, movimiento de tierras y compactación, aumento de pendiente y erosión.

f) Paisaje: perturbaciones de carácter global, enormes escombreras rectilíneas y desnudas de vegetación, huecos de explotación, edificios y plantas de explotación, nuevas vías de comunicación.

En cuanto a la climatología: la investigación llevada a cabo en los archivos municipales sobre los estudios llevados a cabo para la realización de los proyectos indican la acusada continentalidad que rige la zona, con una pluviometría próxima a $500 \mathrm{~mm}$ anuales, una duración media del período frio superior a ocho meses y un periodo cálido inferior a un mes, y gran déficit hídrico de junio a agosto con alguna tormenta importante en cuanto a duración breve e intensidad de cantidad de agua.

Expuestos los cambios ejercidos por la actividad minera, veamos algunas muestras de esa recuperación.

Luis Jiménez Alcaraz (2006: 204) en el capítulo titulado “(1992-1998): Restauración de las explotaciones a cielo abierto", describe la metodología a aplicar en la restauración de las explotaciones mineras en medio ambiente climático mediterráneo, y que resumimos a continuación: La restauración comienza con el relleno de los huecos. A continuación los tractores perfilan el terreno, de acuerdo con el proyecto previsto $\mathrm{y}$ vierten sobre las superficies tierra vegetal. Una vez extendida la tierra vegetal se procede al labrado y abonado con purines, materia orgánica de los afloramientos $\mathrm{u}$ otro abono que produzcan las granjas de la zona. La siembra se realiza en los meses de febrero y marzo y consiste en una mezcla de gramíneas y leguminosas. A los dos años de la siembra se procede a la plantación de árboles y arbustos.

Sin embargo, uno de los principales problemas que plantea cualquier procedimiento de restauración en esta cuenca de clima más continental es la falta de lluvia y las tormentas intensas que arrastran la tierra que todavía no esté suficientemente sujetada por la hierba, produciendo importante erosión, con surcos y pérdida de tierra vegetal.

Para evitar estos estragos y destrucción de los trabajos de recuperación, el Proyecto de Investigación desarrollado por MFU en 1992 en colaboración con la Estación Experimental de Aula Dei del CSIC sobre la metodología a aplicar en la restauración de las explotaciones mineras en ambiente climático mediterráneo trató de resolver dicha cuestión. El proyecto estudió y aplicó el procedimiento para encauzar las aguas cuando hay grandes precipitaciones en un corto espacio de tiempo, desarrollando un sistema 
de cunetas y canales debidamente protegidos contra la erosión. Los cauces conducen a balsas que actúan como grandes depósitos reguladores. Y estas balsas conducen a otras balsas a través de su correspondiente canal. Para la protección de los cauces se utilizan rocas procedentes de la misma excavación. Previo a estos pasos, los estériles que se arrancan durante el avance de la explotación, se vierten en el hueco que queda una vez se ha retirado la capa de carbón. Este método se llama de "transferencia" y se aplicó para la recuperación de la explotación a cielo abierto denominada "Vinagre".

Otros ejemplos de recuperación medioambiental son los proyectos desarrollados en la última década del siglo XX. De algunos de los cuales nos hacemos eco a continuación con información extraída de los archivos municipales:

Proyecto de revegetación de parte de la escombrera de la Mina "Murciélago", 1990

Proyecto de restauración fisiográfica y revegetación de Escombrera. Ayuntamiento de Utrillas, Provincia de Teruel. Abril 1991.

Proyecto de rehabilitación y revegetación de la Escombrera Sur. Utrillas (Teruel). Noviembre 1993.

Proyecto de rehabilitación y revegetación de la Escombrera Barriadas. Utrillas (Teruel). Diciembre 1993.

Proyecto de restauración taludes Escombrera Pozo Santa Bárbara en Utrillas (Teruel) 1995. Proyecto de restauración fisiográfica y revegetación de la escombrara de la Mina la Serna en Utrillas (Teruel) 1995.

Todos estos proyectos comparten la misma finalidad: recuperar las escombreras que se habían originado como consecuencia del vertido de estériles procedentes de las explotaciones mineras llevadas a cabo desde las distintas minas de Utrillas por la empresa Minas y Ferrocarril de Utrillas S.A. durante los años sesenta y setenta.

La inexistencia de normativa al respecto en esa época motivó que los criterios de elección del lugar de vertido fuesen fundamentalmente económicos, abocanándose la más cerca posible a la bocamina. Estos proyectos pretenden recondicionar los terrenos y conseguir un aprovechamiento nuevo y diferente al que corresponde a la situación en la que se encuentran y que integra los siguientes objetivos, tal y como se recogen en las memorias de estos proyectos consultados en el Archivo Municipal del Ayuntamiento de Utrillas:

- Restauración y producción biológica del suelo.

- Reducción, control de la erosión y estabilización de los terrenos sin consolidar.

- Integración paisajística, tan degradada en la actualidad.

- Contribución al desarrollo y enriquecimiento de la diversidad de las especies florísticas.

- Contribución a potenciar la educación ambiental.

Sigue un breve resumen de algunas actuaciones llevadas a cabo sobre recuperación medioambiental: 
Proyecto de revegetación de parte de la escombrera de la Mina "Murciélago", 1990. Se trata de uno de los primeros proyectos de recuperación. Y el procedimiento planteado considera varias actuaciones, respetando las características de la zona. Estas son:

1. Siembra de talud de escombrera con arbustos cuyas características se ajustan a los del terreno tanto en calidad como en composición regular para evitar formación de caminos de agua que pudieran levantarlos, incluyendo la plantación, abonado y primeros cuidados de cada una de las plantas posteriores. Las plantas son: aligustre, acacia, enebro, majuelo, retama, zarzamora, sauce, salís alba...

2. Plantación de cunetas de guarda, siendo las especies: arbustos: avellano (corylus avellana), zarzamora (rubus ulmifolius), majuelo (crataegus monogyna)... y árboles: ailanto (ailantus altissimus), falsa acacia (robinia pseudoacacia), abedul (betula verrucosa) alma blanco (populus alba), olmo (ulmus punilla).

3. Plantación de plataforma de escombrera: árboles: alamo blanco (populs alba), cedro himalaya (cedrus deodora), castaño indias (aesculus hippocastanum), pino larici (pinus nigra)....y arbustos: avellano (corylus avellna); enebro (juniperus oxycedrus), retama (spartium junceum), mimbrera (salix viminalis)...etc.

Se contemplan también elementos decorativos en la entrada de la escombrera:

[...] dos grupos de árboles de gran tamaño (pinos y cipreses) dos en uno de los lados y tres en el otro que junto con la colocación de piedras de gran tamaño, algún otro elemento .decorativo y el fondo formado por el sector 2 en el que se incluyen ciruelo de hoja roja, forsityas y pyracantas de la plataforma de escombrera.

Proyecto de Restauración Fisiográfica y Revegetación de Escombrera. Ayuntamiento de Utrillas, Provincia de Teruel, abril 1991.

Este proyecto se refiere a la Restauración de la escombrera de Mina Santiago y de su ferrocarril minero, situado en la carretera nacional 420 en dirección al municipio de Martin del Rio. Las explotaciones mineras a las que pertenecen la escombrera y el ferrocarril llevan tiempo inactivos. Esta escombrera estaba ubicada a la entrada del casco urbano, y venía utilizándose como vial de paso para camiones procedentes de un cargadero de carbón. Según se lee en la descripción del proyecto, constantemente se producía polvo en suspensión que era arrastrado por el viento hacia las casas cercanas ocasionando serios problemas. Además cuando llovía este polvo, en forma de barro, así como parte de los componentes de la escombrera, eran arrastrados hacia el arroyo rellenando el cauce y provocando la erosión de los aludes próximos. Así mismo varios tramos se utilizaban como vertederos ocasionales de basuras, detritus, chatarras, escombros de obras, etc.

El proyecto pretendía, por una parte, aligerar la pendiente actual de los taludes y proceder a su revegetación con el fin de sujetarlos y a su vez favorecer el entorno 
físico; y, por otra parte, contribuir con el plan del ayuntamiento de acometer mejoras de zonas verdes y ajardinadas y la erradicación de vertidos incontrolados.

Esta labor de restauración y revegetación es constante e incluye otras mejoras, como se ve en los proyectos de 1993 (Proyecto de rehabilitación y revegetación de la Escombrera Sur. Utrillas (Teruel), Noviembre 1993; Proyecto de rehabilitación y revegetación de la Escombrera Barriadas. Utrillas (Teruel), Diciembre 1993) o Proyecto de Restauración taludes escombrera pozo Santa Bárbara en Utrillas (Teruel) de 1995.

En este último también se incluye garantizar el abastecimiento de agua para el riego de las diferentes especies plantadas, con la construcción de una red de riego.

La revegetación se sigue haciendo con especies adaptadas a la zona, así se proponen arbustos de tipo rastrero como cotoneaster, piracanta o sabina rastrera junto a arbustos pequeños como romeros, lavandas y retamas mezclados con otros de mayor porte como ciruelo, tamrix o forsythia, con el fin de disminuir la erosión del suelo y favorecer su fijación en las zonas en las que el talud presenta mayor pendiente.

Ya en nuestro siglo este proceso de recuperación paisajística se mantiene con proyectos de reforestación de las lomas circundantes con el fin de crear una masa de árboles en equilibrio con las condiciones climáticas y edáficas en los alrededores de las zonas afectadas por las explotaciones mineras. Para ello se siguen eligiendo especies autóctonas de porte arbustivo y arbóreo. Las primeras servirán para conseguir una cubierta más rápida, mientras que las segundas tendrán un crecimiento más lento garantizando así la recuperación progresiva de la zona, a la vez que se tienen también en cuenta las zonas más umbrías y las más soleadas a la hora de plantar especies.

Sobre el medio ambiente socioeconómico, ámbito que trataremos a continuación, se advierte que las alteraciones del medio físico afecta a la forma de vida y caracteres culturales de la zona así como a la apertura de nuevas actividades que aumentan la variedad de ofertas y el mantenimiento estable de la zona a largo plazo. Asimismo, las escombreras son zonas que están prácticamente dentro del casco urbano, influyendo negativamente en el medio ambiente.

\section{RECUPERACIÓN SOCIO-ECONÓMICA}

Randó (2004: 22) dibuja muy bien la situación en la que quedaron estas gentes con la decadencia de la actividad minera, principal motor económico:

Describo situaciones, vivencias, sensaciones y conductas de los seres humanos con los que compartí el día a día. Intento dar a conocer algunos perfiles de sus vidas, que tuvieron como escenario las minas de carbón- (...)-Son episodios de hambre, tragedia, dolor, amor y alegría. 
Fernández Clemente (2002), en su obra Utrillas 1785-2000. De la minería a la manufactura. Las minas de la cuenca de Utrillas. Una perspectiva histórica, habla de los esfuerzos de las autoridades o entidades competentes por salvar el futuro económico de la zona. Indica que entre 1966 y 1980, el Instituto Geológico y Minero de España realizó siete estudios sobre los lignitos y entre sus conclusiones se dejó claro que estas minas eran de fácil mecanización, lo cual permitiría un mayor rendimiento. Entonces se acometieron reformas en la cuenca minera - empujadas también por huelgas de los mineros en defensa de una mejora en sus condiciones laborales. Estas mejoras incluyen sobre todo, allá por 1987, la explotación a cielo abierto con la ayuda de enormes maquinas. Este proceso marca las últimas décadas, con protestas por la disminución drástica del empleo y los daños medioambientales- mientras crece la productividad y desciende también la población.

Ante un futuro negro es necesario tomar medidas. El 8 de noviembre de 1988, con una finalidad inicial de gestionar un polígono industrial comarcal y diversos servicios en común, se establece la Mancomunidad de Municipios de la Cuenca Minera Central de Teruel, con sede en Ultrillas. Su lema es claro: "O nos salvamos como comarca, o nos hundimos como pueblos". Dicha Mancomunidad comprende 8 municipios, y junto a los grandes (Utrillas, Montalbán y Escucha) se agrupan los menores de Martin del Río, Palomar de Arroyos, Castel de Cabra, Hoz de la Vieja y Torre de las Arcas, con un total de 9.235 habitantes y una extensión de $363 \mathrm{Km} 2$. Además de la meta central- el mantenimiento del empleo-, se pretende la construcción de un embalse regulador en la cabecera de Martin, la consecución de un segundo grupo en la central, estudios de viabilidad de la transformación del carbón, tratamiento de residuos sólidos, logros de bienestar social, etc...

Las infraestructuras del polígono fueron construidas muy rápidamente por la Dirección General de Aragón (DGA). Se entablaron relaciones con las compañías eléctricas ENDESA y FECSA sobre la térmica y con el grupo Acción Comarcas Mineras del Parlamento Europeo en relación con las pérdidas de empleo en la minería. Sin embargo, mucho de ello queda en entredicho por nuevas leyes, disposiciones o imposibilidad de acceder a los Fondos Estructurales de la Comunidad Europea pudiendo únicamente acogerse al genérico “Objetivo $5 \mathrm{~b}$ destinado al fomento del desarrollo de zonas rurales” del Plan Miner (Fernández Clemente 2002: 19).

Fernández Clemente (2002: 19) señala otro problema para la recuperación de la comarca de Utrillas a la hora de dar soluciones alternativas: las características de la población. Según este autor 1998, solo el 27\% de la población tenía un puesto de trabajo, en su mayoría en los sectores secundario y terciario y casi a partes iguales en industria, construcción y servicios; el resto, son en su mayoría jubilados y pensionistas $(17 \%)$, parados $(4 \%)$, en edad de estudiar (20\%) o mujeres dedicadas a sus labores 
$(22 \%)$, situación que apenas ha mejorado en la actualidad.

Tal y como relata Carol Hausmann (2006) en el Tomo III de su obra Carbón piedra. Un mundo que desaparece. Historia de la minería del carbón, dedicado a la Comarca Cuencas Mineras de Teruel, los años 1980 - 1990 fueron duros para la comarca. El proceso hasta conseguir que un grupo de empresa decidiera considerar la posibilidad de instalarse en la cuenca fue lento, requirió mucho trabajo y nunca llegó a cuajar del todo.

Por un tiempo las noticias en la época eran esperanzadoras como los titulares de los periódicos de la zona mostraba: Diario de Teruel, sábado 29 de julio de 1989: “SODIAR ha confirmado la viabilidad de Mediteruel. El panorama de la cuenca minera puede cambiar si cuajan dos proyectos empresariales en Utrillas".

EL EBRO, 5 abril 1990: “Utrillas cambia de industria. El jueves, 5 de abril [1990] pasará a la historia del pueblo turolense de Utrillas como la fecha en que su economía, y por lo tanto su desarrollo como núcleo rural, dejaba de estar atada al carbón."

Heraldo de Aragón, 26 octubre de 1990: “Acuerdo para industrializar la cuenca minera turolense."

Fue un esfuerzo para "reindustrializar" la zona pero fueron pocas las empresas que surgieron y se consolidaron. La pérdida de empleo y la lucha de los trabajadores también estaban presentes:

Heraldo de Aragón, 28 de diciembre de 1990: “El carbón contra la normativa de reordenación del sector. Tres mil mineros irán a la huelga en enero".

Heraldo de Aragón 17 de abril de 1991: “Minas y Ferrocarriles cerrarán sus puertas antes de dos semanas. El acuerdo permitirá la creación de empleo."

Diario de Teruel 26 de octubre de 1990: “Acuerdo sobre la instalación definitiva de Casting Ros en Utrillas. Los mineros de MFU tienen garantizados sus puestos de trabajo en actividades industriales." Dicha empresa, dedicada a la fabricación de componentes y accesorios de automoción, fundición y mecanización de piezas, fue inaugurada en 1999, y es una de las pocas que lo hicieron.

La generación de empleo y la detención de la despoblación de la zona siguieron- y siguen- siendo una preocupación constante.

La recuperación del Patrimonio Minero es una de sus esperanzas como atracción de turismo y fuente de ingresos. El siguiente apartado va dedicado a este tema.

\section{RECUPERACIÓN DEL PATRIMONIO MINERO}

En las páginas que siguen hablaremos de los esfuerzos que las entidades y personas están llevando a cabo para salvar del olvido la tradición minera de esta querida tierra.

Como escribe Rando (2004: 264), cuyo libro el mismo dice que es un ensayo basado en sus memorias que relata acontecimientos y sucesos reales: 
Es todo un símbolo que permanezca, todavía el monumento al minero de la plaza del pueblo. Esfuerzo del equipo de gobierno del Ayuntamiento por mantener zonas y edificios emblemáticos del inmediato pasado minero para ubicar en ellos un parque temático sobre minería. De la directiva de "Cuenca Mineras" en su empeño por hacer pervivir, superando dificultades, el pasado minero de toda la zona.

La MFU S.A. construyó un conjunto de edificios de carácter social y de uso industrial que cubrieran las expectativas creadas con la construcción del ferrocarril. El núcleo más importante se edificó en el entorno del Pozo Santa Bárbara y en el centro de la localidad de Utrillas.

En este lugar se construyeron el Hospital Minero, para la atención tanto de los accidentados en la mina como la atención sanitaria de la Comarca de la Cuenca Minera Central de Teruel, muy mal comunicada en esa época. Junto a este edificio se construyeron las escuelas de la empresa. Las dos actividades, sanitaria y docente, fueron realizadas por las Religiosas Hijas de la Caridad de San Vicente de Paúl.

El Ayuntamiento de Utrillas consciente de la importancia de la recuperación del patrimonio Histórico - Minero que ha formado parte de su larga historia, ha impulsado en los últimos años la rehabilitación de un conjunto de edificios quealbergan actividades destinadas a dar a conocer la comarca, impulsar y potenciar las actividades culturales, docentes económicas, financieras y turísticas de la zona.

En enero de 2004 presentó el proyecto de Recuperación del Patrimonio Industrial Minero en la Cuenca Minera de Utrillas (Teruel). Hasta entonces habían sido muchas las gestiones realizadas, incluso antes de que MFU S.A cesase su actividad y entregase su Patrimonio al Ayuntamiento. La moción presentada por el Grupo Socialista a la Mesa del Senado el 30 de mayo de 2001 así lo atestigua. En la carta dirigida al Senado y conservada en los archivos del Ayuntamiento de Utrillas leemos:

El Grupo Parlamentario Socialista, al amparo de lo establecido en el artículo 177 del reglamento de la Cámara, solicita la tramitación de la siguiente moción en la Comisión de Economía:

$[\ldots]$ MOCION:

La Comisión de Economía del Senado insta al Gobierno a que autorice al Instituto para la Reestructuración de la Minería del Carbón y Desarrollo Alternativo de las Comarcas Mineras a suscribir el correspondiente Convenio específico para la financiación del proyecto de "Rehabilitación del Patrimonio Histórico Minero de Aragón" presentado por el Ayuntamiento de Utrillas y aprobado por la Mesa de la Minería de Aragón.

Palacio del Senado, 30 de mayo de 2001.

El senador por Teruel. $\quad$ El Portavoz del Grupo Socialista.

Se trata de una acción integral sobre todo el patrimonio industrial de la cuenca minera tanto en el espacio como en el tiempo motivada por la situación actual que viene definida por el fin de la actividad minera, lo cual ha generado nuevas necesidades 
sociales y por ello es preciso buscar la sostenibilidad económica, consolidar nuevas actividades industriales y crear nuevas infraestructuras.

Tal y como se detalla en el proyecto mismo, consultado en el archivo municipal, esta acción integral busca:

[...] la recuperación del patrimonio minero e industrial de la actividad desarrollada en la cuenca minera central desde el comienzo de las actividades, visto desde una perspectiva amplia en el contexto de la minería comarcal e incluso en el ámbito de la comunidad autónoma, no se trata de recuperar tan solo el patrimonio para su uso con una perspectiva turística (...). Esta actuación tiene la perspectiva de crear un Parque temático de la minería del carbón en uno de los focos extractivos más importantes de la minería de España.

Los activos patrimoniales sobre los que pretenden actuar son los siguientes, según se especifica en el proyecto:

1. Ruinas de las reales Fábricas de Vidrio.

2. Varias bocaminas

3. Lavaderos

4. Pozo de santa Bárbara

5. Minas a Cielo abierto

6. Puntos de interés geológico.

7. Edificios singulares: Convento, escuelas, casa de Direccion, etc.

8. Ferrocarril desde Utrillas a lavaderos.

Las iniciativas tomadas por el Ayuntamiento de Utrillas para recuperar el patrimonio minero, tal y como hemos ido comentando, así como la colaboración de asociaciones de la zona, han sido una constante desde el cierre de la actividad minera. Han organizado congresos nacionales sobre el patrimonio geológico minero, cursos de verano en relación con el patrimonio geológico y minero de la provincia de Teruel, cursos de gestores del patrimonio geológico, seminario de arqueología.... Todo ello relacionado con tres objetivos específicos:

1. Rehabilitación de edificios históricos de carácter industrial social.

2. Facilitar iniciativas didácticas de investigación y turísticas.

3. Creación de empleo.

Veamos brevemente algunas de estas acciones.

1. Rehabilitación de edificios históricos de carácter industrial social.

Tres son los edificios principales, destinándoles a un uso cultural, didáctico e investigador: Antiguo Convento de las Religiosas de la Orden Hijas de la Caridad de San Vicente de Paúl, Antiguo Colegio de MFU S.A. y Pozo de Santa Bárbara y Mina Santiago. 
El Antiguo Convento de la Religiosas de la Orden Hijas de la Caridad de San Vicente de Paúl, tras su rehabilitación, cambio de uso para convertirse en Museo de la Minería.

El Antiguo Colegio de MFU S.A. se rehabilitó con el objetivo de cambiar su uso docente por el de equipamiento cultural, y convertirlo en sede del Archivo de Explotación Minera de la Comarca de la Cuenca Minera Central, con exposiciones y residencia de investigadores.

El Pozo de Santa Bárbara y Mina Santiago, con la rehabilitación de la sala de máquinas, sala de calderas, centro de transformación, taller, vestuarios, balsas de agua y chimenea entre otros elementos se recuperó para uso cultural convertido en centro de exposición y ocio acompañado de la construcción en el exterior de un pequeño lago y la pavimentación del paseo.

\section{Iniciativas didácticas de investigación y turísticas}

Entre las iniciativas en marcha o ya finalizadas se hallan el poner el archivo histórico y documental a disposición de la universidad y centros de investigación y el diseñar actividades educativas, de ocio y aventura para fomentar el turismo rural y que complete la visitas didáctico-culturales con la ayuda de la iniciativa privada. Las actividades a desarrollar pretenden abarcar un amplio abanico de posibilidades como son itinerarios de recorridos de caballo, recorridos en bicicleta o senderismo así como los deportes de pesca controlada, tiro con arco o parapente.

\section{Creación de empleo.}

La rehabilitación de los edificios mencionados y la puesta en marcha de actividades suponía uns fuente de trabajo para la población activa de Utrillas

Y ya para terminar y como conclusión quisiera hacer partícipe al lector de algunas líneas extraídas de la memoria del Proyecto de Musealización de las Antiguas Escuelas Pozo Santa Bárbara de Utrillas, Noviembre de 2012. Dichas escuelas eran utilizadas como almacén del Ayuntamiento y su rehabilitación se encuadra dentro del llamado Patrimonio Cultural y Ambiental de Utrillas. Dicho Patrimonio se ve como:

[...] motivo de desarrollo local en donde el patrimonio actúa como complemento a una economía tradicional, potenciando una parte del sector de servicios y creando otro dirigido hacia el diseño y la comercialización de bienes patrimoniales: lo que se ha dado en llamar industrias culturales (p.9).

En la justificación del interés en la creación del museo se habla de motivos económicos, sociales y educativos o de formación. El párrafo con el que se inicia la justificación de los primeros refleja claramente la situación de muchas de nuestras cuencas mineras: 
puntual permitió la destrucción de hoy potenciales bases de despegue económico.

Y continúa:

La propuesta actual debe tender hacia un crecimiento integral, endógeno y controlado del territorio con estudio de recursos particulares y específicos de cada área, incentivando actividades económicas propias que representen potencialidad de progreso y donde el particularismo del producto y la capacidad de producción queda reducida a un territorio concreto haciendo la competitividad limitada (p. 10).

Como motivos sociales se indica que el patrimonio histórico es, ante todo, un valor social. Representa la capacidad de ser, expresarse y reconocerse de una comunidad y en consecuencia entienden que la gestión patrimonial en un municipio debe efectuarse desde los principios de:

- Conservar en cuanto entendemos que es un bien social.

- Divulgar y fomentar en cuanto que se trata de un valor social.

- Actuar de acuerdo al contexto social.

Como motivos educativos o de formación, el "museo es un centro de formación en cuanto recoge todo aquello relacionado con la memoria colectiva que puede ser interpretado y lo trasmite" (p. 10).

En pocas palabras, la acción integral de recuperación de la zona logra dignificar la figura del minero y destacar la importancia que tuvo la minería en Utrillas a nivel social y económico y rescatar ese valor como motor futuro de desarrollo de una identidad cultural propia, transformada en una "imagen" a través de la cual pueden darse a conocer y comunicarse en un mundo tan globalizado y audiovisual.

\section{SUS GENTES Y SU OPINIÓN}

Tras el breve recorrido por los documentos y acciones llevadas a cabo por las instituciones, organizaciones y asociaciones involucradas en esta recuperación de la cuenca minera de Utrillas le cedemos la voz a los ciudadanos y visitantes para conocer su opinión de primera mano como testigos de una realidad que confía en el futuro.

Con este fin, previo diseño de un guión, se llevaron a cabo varias entrevistas con cinco preguntas abiertas en la villa misma de Utrillas en agosto de 2014. El corpus se compone de dos entrevistas a dos jubilados que trabajaron en la mina hasta su cierre; dos ciudadanos, uno empresario y otro trabajador contratado que no trabajaron en la mina pero que han vivido toda o casi toda su vida en Utrillas y han visto el día a día desde la época de prosperidad a la decadencia y el resurgir lento de esta última época; dos turistas / visitantes que han estado en Utrillas en varias ocasiones; y dos profesionales de la enseñanza que sin ser de Utrillas llevan años ejerciendo dicha profesión en la Comarca y conocen la realidad de los padres y los hijos y, desde su 
posición, son testigos excelentes para hablar del futuro de la juventud en la comarca minera de Utrillas.

Veamos los resultados.

\section{Opinión de mineros jubilados.}

El primer entrevistado, llegó a Utrillas para trabajar en la mina en la época de la actividad minera como tantos otros. Trabajó durante 22 años en la misma y fue prejubilado. El segundo, nacido en Utrillas, trabajó durante 17 años en las minas hasta su cierre. Sus respuestas coinciden casi cien por cien por lo que ofrecemos un resumen de ambas para evitar repeticiones.

1. ¿A nivel general qué cambios ha observado tras el cierre de las minas y de MFU S.A.? (por ejemplo, en cuanto al paisaje, la economía, o los edificios)

El cierre de las minas supuso un fuerte parón económico y un descenso de la población importante ante un futuro que se veía muy negro porque todo giraba en torno a la actividad minera. En cuanto al entorno, el paisaje había sido completamente desfigurado y se fue degradando aún más poco a poco; la reforestación fue malísima en los primeros años tras el cierre y no se cuidaron tampoco los edificios ni el equipo minero o las herramientas. Poco a poco se empezó a recuperar el Pozo de Santa Bárbara y sus alrededores, pero se empezó tarde.

2. ¿Qué opina de la recuperación medioambiental? Según su opinión ¿qué se ha hecho? ¿Podría citar alguna acción que le guste? ¿Y alguna acción que NO le guste? ¿Qué cambios o mejoras propondría?

La recuperación medioambiental no se ha hecho bien porque solo el Ayuntamiento se ha hecho cargo de la repoblación en lugar de hacerlo la MFU S. A. Y en cuanto a la repoblación, no ha habido mantenimiento y en algunos casos ha servido de poco.

Como mejoras propondrían seguir repoblando con el mantenimiento adecuado y evitando el pastoreo en lo repoblado.

3. ¿Qué opina de la recuperación de edificios y servicios? Según su opinión ¿qué se ha hecho? ¿Podría citar alguna acción que le guste? ¿Yalguna acción que NO le guste? ¿Qué cambios o mejoras propondría?

La empresa propietaria de muchos de esos edificios era la MFU S.A. y se fue sin más cuando se le debería haber obligado a reforestar y a mantener o donar los edificios al municipio entonces mismo. Todo quedó derruido y sin ningún cuidado. Poco a poco se van recuperando edificios emblemáticos para el pueblo como la escuela antigua que estaba en la mina o el Pozo de Santa Bárbara y la Mina Santiago. Se ha abierto el museo minero, se ha recuperado la locomotora de vapor antigua llamada Hulla de 1904. Es una labor que se va haciendo poco a poco con escasos recursos.

4. ¿Qué opina sobre la recuperación económica? Según su opinión ¿qué se ha hecho? ¿Podría citar alguna acción que le guste? ¿Y alguna acción que NO le guste? 
¿Qué cambios o mejoras propondría? ¿Cómo ha evolucionado la población?

La recuperación ha sido lenta, mala y sin control. Se hizo la reconversión con la apertura de varias empresas de distintos sectores gracias a los fondos MINER: metalúrgicos, cárnicos, de construcción...para dar trabajo a la gente. Sin embargo, en opinión de uno de uno de los mineros, ello atrajo a empresas que vinieron, montaron sus industrias, y cuando obtuvieron una subvención se marcharon. Gracias a algunas que se quedaron la población se va manteniendo tras el fuerte descenso del cierre definitivo, evolucionado con subidas y bajadas.

5. ¿Le gusta vivir en Utrillas? ¿Por qué? ¿Qué es lo que más le gusta? ¿Y lo que menos? ¿Propondría algunos cambios o medidas para el futuro? ¿Cuáles?

Ambos encuestados comentan que les gusta vivir en Utrillas bien porque lleva ya muchos años viendo allí (22 años), bien porque es el único lugar en el que ha vivido y lo mejor para ambos son sus gentes y la tranquilidad con la que vive así como los servicios que tienen. $Y$ lo que menos les gusta es la escasez de trabajo y posibilidades de mejora económica. Añoran cuando funcionaban las minas y había más personal, trabajo, animación...

Opinión de empresarios y trabajadores de la zona.

Se trata de una persona con un negocio familiar y de un trabajador, ambos de Utrillas, de 41 y 49 años respectivamente. Veamos sus opiniones resumidas:

1. ¿A nivel general qué cambios ha observado tras el cierre de las minas y de MFU S.A.? (por ejemplo, en cuanto al paisaje, la economía, o los edificios)

Ambos coinciden en que quedó un paisaje desértico, los edificios se fueron deteriorando y la población comenzó a irse por falta de trabajo. Los que se quedaron con trabajo ganaban mucho menos que en la mina.

2. ¿Qué opina de la recuperación medioambiental? Según su opinión ¿qué se ha hecho? ¿Podría citar alguna acción que le guste? ¿Y alguna acción que NO le guste? ¿Qué cambios o mejoras propondría?

La recuperación medioambiental la consideran poca y lenta. Se intentaron recuperar las escombreras de explotaciones a cielo abierto plantando pinos, carrascas cerezos.... pero la falta de atenciones posteriores - como por ejemplo el riego- ha hecho que no hayan sido tan eficaces como se pretendía. Comentan que con la ayuda de subvenciones quizá se pudieran realizar acciones para mejorar paisajes degradados y crear también empleo, pero no se muestran muy confiados por los tiempos que corren.

3. ¿Qué opina de la recuperación de edificios y servicios? Según su opinión ¿qué se ha hecho? ¿Podría citar alguna acción que le guste? ¿Y alguna acción que NO le guste? ¿Qué cambios o mejoras propondría? 
Ambos se muestran satisfechos con la recuperación de varios edificios y adecentamiento de otras zonas, aunque - como la mayoría de los encuestadosconsideran que la MFU S. A. debería haberse preocupado más de su patrimonio y no dejarlo decaer de ese modo. Lo importante ahora es la conservación de lo hecho y su promoción para atraer turismo e investigadores e ir levantando a la zona poco a poco.

4. ¿Qué opina sobre la recuperación económica? Según su opinión ¿qué se ha hecho? ¿Podría citar alguna acción que le guste? ¿Y alguna acción que NO le guste? ¿Qué cambios o mejoras propondría? ¿Cómo ha evolucionado la población?

Ambos coinciden en que es lenta y costosa, con empresas que llegaron gracias a subvenciones y desaparecieron tras cobrar sin dar el prometido trabajo a los antiguos trabajadores de las minas. En la actualidad consideran que se ha llegado a cierto equilibrio y que la empresas que hay se van manteniendo y los negocios familiares o pequeñas empresas progresan ligeramente al ser Utrillas la capital administrativa de la Comarca de las Cuencas Mineras y disponer de servicios generales como supermercados, farmacias, instituto de bachillerato, centro de salud, centro deportivo... que atrae a la gente de toda la comarca.

5. ¿Le gusta vivir en Utrillas? ¿Por qué? ¿Qué es lo que más le gusta? ¿Y lo que menos? ¿Propondría algunos cambios o medidas para el futuro? ¿Cuáles?

La respuesta es unánime: les gusta vivir en Utrillas. No han tenido necesidad de emigrar como tantos otros y que poder salir a la calle y saludar a la gente y pararse a charlar es un privilegio. Disponen además de todos los servicios que necesitan y ello hace la vida mucho más cómoda. Mencionan el descenso de población desde unos 5000 hasta unos 3.300 que tiene en la actualidad, y las pocas perspectivas para los jóvenesun mal general- pero también comentan que en la provincia de Teruel, Utrillas es uno de los pocos municipios que ha experimentado un aumento de población en los últimos años.

\section{Opinión de dos visitantes}

Son visitantes frecuentes por cuestiones familiares y de amistad y que conocieron la zona tras el cierre de las minas y en plena degradación. El primer entrevistado es hombre de 56 años, y la segunda es mujer de 57 años. Ambos son funcionarios de la Administración Central en una gran ciudad. Sus opiniones de nuevo coinciden bastante. Sigue un resumen:

1. ¿A nivel general qué cambios ha observado tras el cierre de las minas y de MFU S.A.? (por ejemplo, en cuanto al paisaje, la economía, o los edificios)

Limpieza del aire y del paisaje que ha perdido ese manto negro y olor característico y limpieza de edificios y calles. 
A nivel económico el cierre de las minas y de MFU afectó muy negativamente. Hubo prejubilaciones de trabajadores con edades muy jóvenes y con un gran poder adquisitivo, y por el contrario los jóvenes de la zona minera se encuentran a día de hoy sin muchas expectativas del mercado de trabajo. Sin duda, el cambio ha sido muy importante y la suerte ha estado en el Plan Miner de la UE y la llegada de la empresa Casting Ros y el ciclo de abro-cierro de otras empresas, pero la zona sigue económicamente deprimida, aunque resurgiendo poco a poco.

2. ¿Qué opina de la recuperación medioambiental? Según su opinión ¿qué se ha hecho? ¿Podría citar alguna acción que le guste? ¿Y alguna acción que NO le guste? ¿Qué cambios o mejoras propondría?

Positiva pero como siempre mejorable. Las minas a cielo abierto han recuperado el paisaje, así como los lavaderos. Pero es necesario seguir con la recuperación del paisaje alrededor de la zona minera.

3. ¿Qué opina de la recuperación de edificios y servicios? Según su opinión ¿qué se ha hecho? ¿Podría citar alguna acción que le guste? ¿Y alguna acción que NO le guste? ¿Qué cambios o mejoras propondría?

Es la mejor forma de no perder lo que en su día fue la seña de la vida minera. La rehabilitación del edificio que se ha destinado al alojamiento de visitantes e investigadores, el museo minero para no olvidar lo que significó la mina para todo el pueblo y alrededores, así como el trenecito destinado para el disfrute de los ciudadano son pasos importantes. Pero falta mucho por hacer. Las naves vacías que hay en el entorno no son muy interesantes; más bien sirven para denunciar la falta de actividad. La mejor propuesta de futuro es potenciar lo ya hecho y continuar en la recuperación de lo que queda pendiente.

4. ¿Qué opina sobre la recuperación económica? Según su opinión ¿qué se ha hecho? ¿Podría citar alguna acción que le guste? ¿Y alguna acción que NO le guste? ¿Qué cambios o mejoras propondría? ¿Cómo ha evolucionado la población?

El asentamiento de la industria Casting Ros, la alimentaria Espuña, y alguna otra empresa de servicios ha paliado un poco la recuperación económica, pero en este momento es insuficiente y no puede absorber el paro tanto juvenil como parados de larga duración.

Se han hecho y se siguen haciendo esfuerzos por parte de la administración local y regional, pero el ofrecer duros a cuatro pesetas atrae a mucho desaprensivo (especulador) que cuando ha obtenido lo que buscaba abandona. Hay que pensar que el Plan Miner desaparecerá y lo que no esté hecho se quedará sin hacer.

5. ¿Le gusta vivir en Utrillas? ¿Por qué? ¿Qué es lo que más le gusta? ¿Y lo que menos? ¿Propondría algunos cambios o medidas para el futuro? ¿Cuáles?

Aunque no han vivido en Utrillas, opinan que vivir en Utrillas es cómodo, sobre todo para parejas jóvenes con niños en edad escolar o gente que le guste la vida tranquila 
y los jubilados. Es como vivir en un pueblo grande con acceso a servicios deportivos, culturales y educativos. Los servicios médicos quizá deben mejorar con más personal médico especializado.

Opinión de profesionales de la enseñanza.

Son dos profesores de EGB, ninguno nacido en Utrillas pero que llevan 11 años ejerciendo como maestros en Utrillas o Montalbán, pueblo cercano y cabeza de partido. Sigue un resumen de sus opiniones.

1. ¿A nivel general qué cambios ha observado tras el cierre de las minas y de MFU S.A.? (por ejemplo, en cuanto al paisaje, la economía, o los edificios)

Se han rehabilitado algunos edificios relacionados con las minas para su apertura al turismo. La economía ha sufrido un cambio negativo ya que hay familias que se han tenido que marchar en busca de empleo a pesar de los trabajos que se han creado para la reconversión minera con fondos europeos del Plan Miner (Casting Ros o Espuña más recientemente), pero en su opinión los esfuerzos han sido escasos.

2. ¿Qué opina de la recuperación medioambiental? Según su opinión ¿qué se ha hecho? ¿Podría citar alguna acción que le guste? ¿Y alguna acción que NO le guste? ¿Qué cambios o mejoras propondría?

Ambos profesionales opinan que se ha hecho poco ya que si piensan en el recuerdo que tienen de cuando llegaron, todo les parece casi igual. Como medidas de futuro propondrían más vegetación, más zonas verdes tanto en el propio pueblo como en los alrededores para quitar esa apariencia de zonas desérticas que se ven en algunos puntos.

3. ¿Qué opina de la recuperación de edificios y servicios? Según su opinión ¿qué se ha hecho? ¿Podría citar alguna acción que le guste? ¿Y alguna acción que NO le guste? ¿Qué cambios o mejoras propondría?

En cuanto a la recuperación de edificios la consideran muy positiva resaltando junto a otros edificios recuperados la residencia de investigadores "José Luis Alegre", pero lamentando que de momento se use solo para el alojamiento de grupos muy concretos llegados gracias al Ayuntamiento (por ejemplo, grupos artísticos que vienen por el "Verano Cultural"), lo cual resulta muy caro ya que casi todo el año permanece cerrada. Consideran que hay una mala gestión de este centro y debería abrirse más al público. Otras acciones que destacan son la puesta en marcha del "Tren turístico" que recorre un pequeño trayecto desde la mina hasta el Museo Minero, pero temen por su continuidad y mantenimiento.

En su opinión, Utrillas es un pueblo con muchos recursos, pero la gente no sabe, en muchas ocasiones, aprovecharlos. Hay piscina cubierta, Escuela de Idiomas, Escuela 
Infantil, Biblioteca, Pabellón Deportivo. Se hacen actos culturales y el público es escaso para la población que tiene. Se quejan de que el Ayuntamiento, en ocasiones, no hace una buena gestión para su desarrollo.

Como propuestas, señalan la ampliación de aquellos servicios que hay más demanda (por ejemplo, escuela infantil) y un cambio de gestión para una mayor repercusión y un incremento económico.

4. ¿Qué opina sobre la recuperación económica? Según su opinión ¿qué se ha hecho? ¿Podría citar alguna acción que le guste? ¿Y alguna acción que NO le guste? ¿Qué cambios o mejoras propondría? ¿Cómo ha evolucionado la población?

Sobre la recuperación económica consideran que ha sido escasa ya que se centra especialmente en una empresa, la Casting Ros, que ha absorbido casi todos los puestos de trabajos de la zona. La economía depende de la producción de dicha empresa. Indican que ha disminuido la población joven y que muchos de los trabajadores de las minas fueron prejubilados bastante jóvenes con un buen sueldo y se quedaron en Utrillas aunque no hubiesen nacido allí. Gracias a esas buenas condiciones de prejubilación piensan que la crisis en las personas se ha notado menos que en otras zonas porque los prejubilados de las minas ayudan económicamente a sus familias con sus pensiones.

5. ¿Le gusta vivir en Utrillas? ¿Por qué? ¿Qué es lo que más le gusta? ¿Y lo que menos? ¿Propondría algunos cambios o medidas para el futuro? ¿Cuáles?

A ambos les gusta vivir en Utrillas pues combina tranquilidad y compatibilidad con el trabajo y servicios disponibles. Lo que más les gusta es la disponibilidad inmediata de recursos básicos. Lo que menos son escasez de actividades para niños. Como propuesta creen que el Ayuntamiento en colaboración con la biblioteca debería ofertar más actividades culturales para la población infantil.

Cerramos este apartado con la opinión de un utrillense, hijo de minero, que emigró en su juventud y visita esporádicamente el lugar que le vio nacer y crecer, pero donde no espera regresar y que refleja el sentir de otros muchos que se fueron tras el cierre y de las minas y decadencia de la zona:

No tiene sentido que hable sobre el lugar en el que nací y viví los primeros años y en el que ví a mi padre trabajando en la mina y sufriendo al final de sus días por enfermedad contraída "gracias" a su trabajo en la mina. No vivo allí, ni conozco la dinámica de los acontecimientos, ni la estructura empresarial - laboral, etc. Solo sé que está la Casting Ros como gran empresa que aglutina una buena cantidad de mano de obra. Hubo otras empresas en algún mini-polígono que desaparecieron pronto. Ahora hay algunas nuevas empresas. Pero no vivo allí y apenas conozco los interés de la gente.... 


\section{CONCLUSIÓN}

Con este artículo hemos intentado un acercamiento a la realidad tras el cese la actividad minera en la Comarca de Cuencas Mineras de Teruel, tomando como ejemplo la Villa Real de Utrillas. El principal motivo que hemos perseguido ha sido provocar la reflexión sobre cuestiones que afectan al entorno y la vida de sus habitantes: el impacto medioambiental, el desamparo, la despoblación, el paro...y la obligación de decidir entre la destrucción del entorno o de abogar por un crecimiento sostenible manteniendo la biodiversidad. Los pasos dados hasta ahora indican un lento avance hacia una economía sostenible basada en un crecimiento integral, endógeno y controlado del territorio y de sus gentes, y tratando de hacer realidad las palabras de Juan Ignacio Artieda (2006:34), Presidente de Carbounión por aquel entonces: energía, ecología y economía, son los tres pilares sobre los que se apoya hoy el desarrollo y, en consecuencia, la paz.

La opinión de sus ciudadanos y una visita a Utrillas deja constancia de ello: espacios verdes para pasear y disfrutar del entorno una vez negro, edificios y construcciones mineras recuperadas con fines didácticos y de entretenimiento, nuevos servicios creados para uso de toda la Comarca: Instituto de Bachillerato, Escuela de Idiomas, Escuela Infantil, Biblioteca, Pabellón Deportivo, Centro de Salud, o nuevos descubrimientos geológico e interés por los investigadores (restos de dinosaurios, ámbar de San Just). Pero también, falta de entusiasmo por parte de las empresas y la administración por embarcarse en acciones emprendedoras y duraderas, escasez de trabajo, emigración de la población juvenil, especulación empresarial... Se percibe un renacer, pero lento.

El título elegido para estas líneas fue inspirado en el artículo de Arturo San Agustín (2002) "Hay vida después de la mina”, cuyo retrato del minero es una prueba más del afán de estas gentes utrillenses, y con sus palabras terminamos:

El minero es un poeta tiznado. $Y$ a la vez un valiente, un pequeño héroe, un gran emprendedor. Desde el momento en el que se mete en el agujero tiene que empezar a detectar todo aquello que puede conducirle a la muerte. Es, pues, un emprendedor total.

Esperamos que este estudio sobre Utrillas como reflejo de las Cuencas mineras, sea un ejemplo más de su constate empeño por hacer pervivir el pasado minero de la zona y que estos duros e inhóspitos paisajes para el visitante sean de nuevo ejemplo de lo que un día fueron capaces: de acoger primero y convivir después con gentes de todo el mundo. Teruel existe y en él está Utrillas, como capital administrativa de la Comarca de Cuencas Mineras turolenses luchando por renacer de sus cenizas. Vaya desde aquí mi agradecimiento a la corporación municipal por permitirme acceder a sus archivos y facilitarme información y a todas aquellos utrillenses y visitantes que amablemente se ofrecieron a contestar a mis preguntas en el verano de 2014. 


\section{Bibliografía}

Albero Gracia, J. (2002): 100 años de la Constitución de la Compañia Minas y Ferrocarriles, Zaragoza, Calvia.

Archivo del Ayuntamiento de Utrillas.

Artieda, J. I. (2006): “Utilización racional de los recurso naturales”, en C. Haussman Tarrida (ed.) (2006) Carbón de Piedra. Un mundo que desaparece (Tomo III), Utrillas (Teruel), Comarca de Cuencas Mineras, 190-200.

Asociación de Amigos del Museo Minero de Utrillas en www.minasutrillas.com (Consultado en agosto de 2014). Ayuntamiento de Utrillas.http://www.utrillas.es/InternetRural/Utrillas/ home.nsf/menu/pueblo (Consultado en agosto de 2014).

Fernández Clemente, E. (1999): Utrillas 1785-2000. De la minería a la manufactura, Utrillas (Teruel), Casting Ros S.A.

Hausmann Tarrida, C. (Ed). (2006): Carbón de Piedra. Un mundo que desaparece (Tomo III), Utrillas (Teruel), Comarca de Cuencas Mineras.

Hausmann Tarrida, C. (Ed.) (2006): Carbón de Piedra. Un mundo que desaparece (Tomo IV). Utrillas (Teruel): Comarca de Cuencas Mineras.

Jiménez Alcaraz, L. (2006): “(1992-1998). Restauración de las explotaciones a cielo abierto", en C. Hausmann Tarrida (ed.) (2006) Carbón de Piedra. Un mundo que desaparece (Tomo III), Utrillas (Teruel), Comarca de Cuencas Mineras, 204.

Randó Corella, F. (2004): Un valle de cenizas. Utrillas (Teruel), Comarca de Cuencas Mineras.

San Agustín, A. (2002), “Hay vida después de la mina”. El Periódico, 24 de diciembre de 2002, 8.

Tren minero de Utrillas. https://www.facebook.com/museoyferrocarrildeutrillas (Consultado en agosto de 2014). 